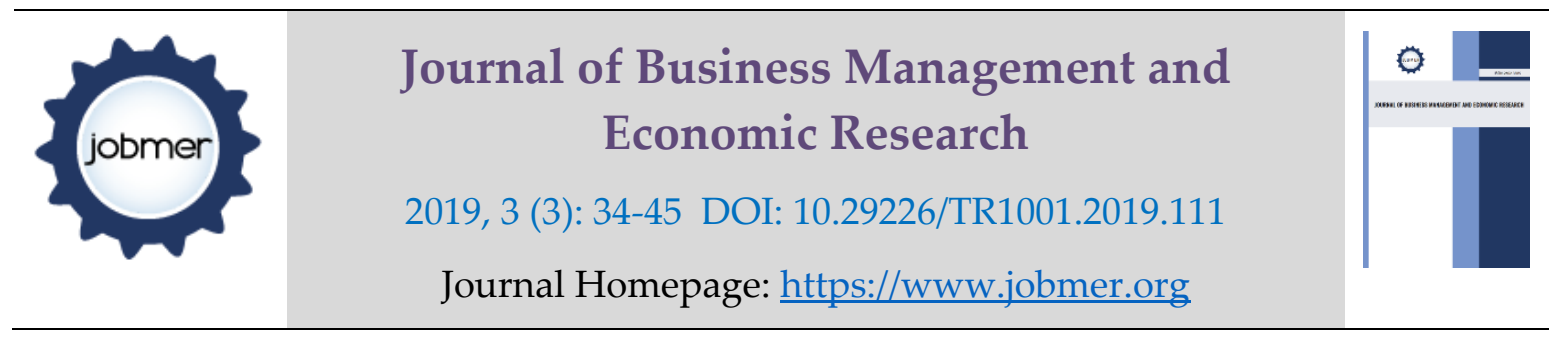

\title{
Determinants of Linking Gaps Tea Production: Case Study of Tea Production Households in Northern Midland and Mountainous Region, Vietnam
}

Nguyen Nhu Trang

Thai Nguyen University of Economic Business administration

Nhutrang226@tueba.edu.vn

\begin{abstract}
Small-scale, outdated, fragmented production and individuals are typical characteristics of agricultural production in Vietnam. These features have caused difficulties for farmers in agricultural production in general and are barrier to the application of technology for farmers in particular. In fact, linkages between agricultural production households are needed, but at present, the linkage status is still low and rather loose. This study aims to identify factors affecting the production linkages decision of GAPs tea farmers in the Northern Midlands and Mountains region. Results from using probit models have shown that low-experienced households, low levels of education, production technical conditions to apply low GAP standards tend to be associated together, at the same time, the characteristics of the household head who are members of socio-political organizations also have a positive influence on the decision to link production of GAPs tea households. ...
\end{abstract}

Keywords: Determinants, Linkages, GAPs tea production, Northern midland and mountainous region...

\section{Introduction}

For centuries, tea has been known as a good drink for health, commonly used in many countries around the world. Vietnam is known as one of the 10 leading countries in tea production in the world with 34/64 tea growing provinces. Northern Midlands and Mountains region is known as the region with the largest tea area in Vietnam, and also has biggest tea area applying the good agricultural practices throughout the country, in which Thai Nguyen, Yen Bai and Phu Tho provinces are the most popular and famous. GAPs tea area in three provinces accounts for more than $50 \%$ of GAPs tea area of Vietnam. Currently, GAPs tea 
production is an inevitable direction of the tea industry, to produce quality and safe products for consumers, protect the health of producers. However, tea production is still fragmented, backward and not properly production organized so it has not fully exploited the potential economic value of the tea industry. Many tea producing households can not sell their GAPs tea with proper price thus they have to sell fresh tea at low prices equal to the price of normal tea, while processors have not been interested in fresh tea materials produced under GAPs standards. The situation that tea processors force the purchase price of fresh tea very low is quite popular today. Consumers do not have information about GAPs tea production or less trusting in GAPs tea production due to the link between GAPs tea growers and processors and sellers are loose and non-transparent. This is one of the important reasons leading to the phenomenon that only more than $0.5 \%$ of households apply and maintain GAPs tea production in the country after 10 years of implementing GAP standards for tea production in Vietnam Previous studies on tea have conducted research directions such as assessing the level of association in tea production by Ngo (2015); researching on the issue of tea production and consumption, Tran (2010), Nguyen (2014), Ta (2010); researching on tea production according to GAP standards (Pham, 2014); Research on tea's technical efficiency of Hong and Yabe (2015)... However, research on factors affecting the production linkage in GAP standard tea production has not been studied. Therefore, this research is done to fill this research gap.

\section{Conceptual framework}

This paper use Peasant economics theory Frank Ellis (1980). Ellis (1980) explains economic behaviors of farmers by providing reasonable assumptions on the household's purposes and the nature of the markets in which householdsare a decision maker. The theory studies economic behaviorsof farm householdsfrom two perspectives: intra-household interactions and extebrnal interventions. Interactions within the household mainly refer to effects of gender, age, labour, land use, production technology of the households. This theory suggests that the main factorsof production such asland, labor, and technology is a main source of farmer productivity. In this theory, the farmer households are part of the socio-economic system; therefore, their economic behaviors as agricultural producers aredepenedand 
influenced by the system. Production decisions of farm households are affected by political economy, government policies and regulations, environmental issues, and market factors... (Eliis, 1980) also confirms that the household is an economic factor, and the decision of household on producing goods is made as a rational factor in the market economy. Then, the decision of householdsare based on: (i) factorsof production held by the households; (ii) technology selected; (iii) market and (iv) government policy.

Base on theory of Ellis (1980) and household decision conceptual framework of FAO (1995), paper use the model which are discribed in the following figure.:

Figure 1: Framework of farmer's decision

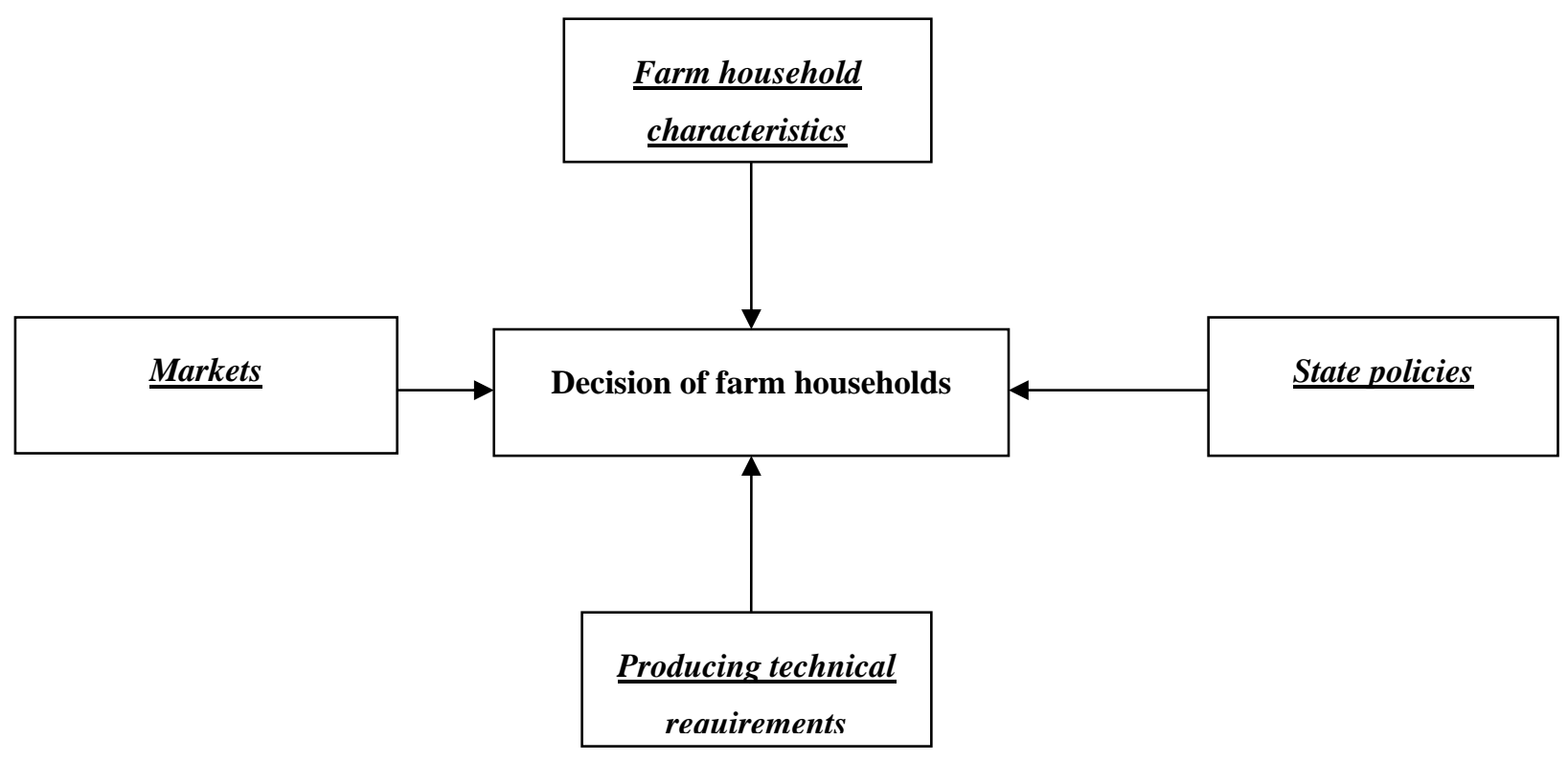

\section{Methodology and data}

\section{Methodology}

Theoretical framework indicates that linkages choice in producing GAPs tea of the farm households are affected by many factors that can be grouped into four categories: characteristics of household head, Producing technical requirement, market conditions, and government policies. Since the choice or decision of households in linkages producing GAPs tea is a discrete choice, which show whether a household adopts linkages or not, a probit model should be used to achieve the research objectives. The Probit model has its forms as 
follows:

$$
\begin{aligned}
& \text { pi }=\operatorname{prob}(\mathrm{Yi}=1 \mid \mathrm{X})=\int_{-\infty}^{\mathrm{xi} \beta} 2 \pi^{-\frac{1}{2}} \exp \left(-\frac{t^{2}}{2}\right) d t \\
& =\Phi(\alpha+\mathrm{H} \beta+\mathrm{F} \gamma+\mathrm{M} \theta+\mathrm{P} \delta+\varepsilon)
\end{aligned}
$$

where $\mathrm{p}_{\mathrm{i}}$ is probability of choosing the linkages producing GAPs tea $\left(\mathrm{Y}_{\mathrm{i}}=1\right)$; $\Phi$ represents the cumulative distribution of a standard normal random variable; $\mathrm{X}$ is a vector of determinants on the linkages producing GAPs tea production, which includes vectors $\mathrm{H}, \mathrm{F}$, $\mathrm{M}$, and $\mathrm{P} ; \mathrm{H}$ is a vector of household head characteristics; F presents a vector of technical condition; $\mathrm{M}$ and $\mathrm{P}$ is vectors of market conditions and state policies, respectively; and $\varepsilon$ is error terms.

To estimate the impacts of determinants on probability of choosing the linkages producing GAPs tea, the marginal effect should be calculated, and it accounts for a partial change in the probability. The marginal effect associated with continuous explanatory variables $\mathrm{X}$ on the probability $\mathrm{P}\left(\mathrm{Y}_{\mathrm{i}}=1 \mid \mathrm{X}\right)$, holding the other variables constant, can be derived as follows:

$$
\frac{\partial \mathrm{Pi}}{\partial \mathrm{Xik}}=\varphi\left(\mathrm{xi}^{\prime} \beta\right) \beta \mathrm{k}
$$

$\varphi$ represents the probability density function of a standard normal variable. The marginal effect on dummy variables should be estimated differently from continuous variables. Discrete changes in the predicted probabilities constitute an alternative to the marginal effect when evaluating the influence of a dummy variable (Greene, 2011). Such an effect can be derived from the following:

$$
\Delta=\varnothing \overline{(X} \beta, d=1)-\varnothing \overline{(X} \beta, d=0),
$$

The marginal effects provide insights into how the explanatory variables shift the probability of frequency of famer's decision (Greene, 2011). The marginal effects are calculated for each variable while holding other variables constant at their sample mean values.

Factors influencing farmer's choice with a new producing alternative method may include: characteristic of farmer household, technical requirement, market and state policies (Ellis, 1980). In previous studies Abdulai et al(2008), Sriwichailamphan (2008), Joseph (2013), Pong Thong (2014), Thang (2018)..., characteristics such as gender, age, education, household size, ethnicity, price, and advertising... are handled as explanatory variables. In 
this paper, characteristic of household heads and households, technical requirements, market condition, and state policies affect the decision of households whether applying linkages producing in GAPs tea or not.

\section{Research areas}

The Northern Midland and Mountainous (NMM) region is the largest tea-producing areas in Vietnam and its total tea-planting areas is 96526.9 hectares (GSO, 2017). This region includes provinces that are well-known in terms of the quality of tea products and the teaexporter such as Thai Nguyen, PhuTho, Yen Bai, Tuyen Quang, Ha Giang, Son La...

Thai Nguyen, Yen Bai and Phu Tho provinces are located in the center of the region with tea-growing areas of 21361 ha, 11000ha and 16000ha, respectively. According to the development master plan on tea production by 2020, total areas of GAPs tea of the region reach to 28971 ha, of which the GAPs tea areas of the three selected provinces are 17300 hectares, in which Thai Nguyen is 2000 hectares, PhuTho is 6500, Yen Bai is 8800 hectares, and they account for $59.71 \%$ of the total areas producing GAPs tea in Vietnam.

\section{Data}

A survey is conducted to collect data from GAPs tea-producing households, including both linkages producing GAPs tea and single manner in the three selected provinces. 167 GAPs tea households are selected and directly interviewed by structured questionnaires. The collected data are presented in table below:

Table 1. Description of the surveyed sample

\begin{tabular}{lcccc}
\hline & Mean & Std. Dev. & Min & Max \\
\hline Thai Nguyen province (\%) & 40.0 & 0.5006 & 0 & 1 \\
Yen Bai province (\%) & 23.63 & 0.3966 & 0 & 1 \\
Phu Tho province (\%) & 36.36 & 0.4555 & 0 & 1 \\
\hline
\end{tabular}




\begin{tabular}{lcccc}
\hline Male household head & 75.45 & 0.4316 & 0 & 1 \\
Age of household head (year) & 49.89 & 8.4001 & 26 & 68 \\
Kinh groups (\%) & 77.84 & 0.4165 & 0 & 1 \\
High school education and above (\%) & 28.14 & 0.4510 & 0 & 1 \\
Member of social political organizations (\%) & 64.07 & 0.4812 & 0 & 1 \\
Household Laborers (labor) & 3.77 & 1.1215 & 1 & 6 \\
Distance to district center (km) & 11.99 & 6.3838 & 1.3 & 30 \\
Linkages producing GAPs tea (\%) & 65.86 & 0.4755 & 0 & 1 \\
\hline
\end{tabular}

The surveyed sample consists of 167 GAPs tea-producing households located in the three selected provinces, including Thai Nguyen (40.0\%), PhuTho (36.36\%) and Yen Bai (23.63\%). Of which, $75.44 \%$ of household heads are male, and $77.84 \%$ of surveyed household head are Kinh ethnic group. 28.14\% of the surveyed household heads obtain high school education and above, and 64.07\% of them are members of social-political organizations at communal and village levels. In the sample, $65.86 \%$ of tea-producing households are linkages producing the GAPs tea.

\section{Results}

The data used in the probit model are tested for multicollinearity. The correlation matrix shows that there is no evidence of strong correlation between these independent variables, thus those independent variables are exogenous. Using the probit model and its marginal effects specified in the section 3 , the paper estimates the probability that households select linkages in producing GAPs tea. Empirical results are presented in Table 2.

Table 2. Determinants of GAP standards in production of tea-producing farmers 


\begin{tabular}{|c|c|c|}
\hline & $\Phi(\mathbf{Y}=\mathbf{1} \mid \mathbf{X})$ & $\begin{array}{l}\text { Marginal effect } \\
\qquad(\mathrm{dy} / \mathrm{dx})\end{array}$ \\
\hline \multirow[t]{2}{*}{ Gender } & 0.2399 & 0.0617 \\
\hline & $(0.3465)$ & $(0.0937)$ \\
\hline \multirow[t]{2}{*}{ Age } & -0.0175 & -0.0042 \\
\hline & $(0.0244)$ & $(0.006)$ \\
\hline \multirow[t]{2}{*}{ Ethnicity } & 0.0322 & 0.0078 \\
\hline & $(0.3842)$ & $(0.0949)$ \\
\hline \multirow[t]{2}{*}{ Education } & $-0.7104 *$ & $-0.1976 *$ \\
\hline & $(0.3651)$ & $(0.1144)$ \\
\hline \multirow[t]{2}{*}{ Member of social political organizations } & $0.6649 *$ & $0.1757 *$ \\
\hline & $(0.3457)$ & $(0.0957)$ \\
\hline \multirow[t]{2}{*}{ Tea-producing experience } & $-0.069 *$ & $-0.0167 *$ \\
\hline & $(0.0266)$ & $(0.0061)$ \\
\hline \multirow[t]{2}{*}{ Household laborers } & $0.4815^{* *}$ & 0.1168 \\
\hline & $(0.1798)$ & $(0.0434)$ \\
\hline \multirow[t]{2}{*}{ Distance to centre district } & $-0.0823 * *$ & -0.0199 \\
\hline & $(0.0283)$ & $(0.0067)$ \\
\hline \multirow[t]{2}{*}{ Tea-growing farm areas } & $1.997^{*}$ & $0.0 .4848 *$ \\
\hline & $(0.7754)$ & $(0.1860)$ \\
\hline
\end{tabular}




\begin{tabular}{lcc}
\hline Advertisement manner & -0.8734 & -0.2788 \\
& $(0.5905)$ & $(0.221)$ \\
Support capitals & $1.771^{* * *}$ & $0.4751^{* * *}$ \\
& $(0.4660)$ & $(0.1045)$ \\
Technical conditions & $-0.3694^{* *}$ & $-0.0896^{* *}$ \\
& $(0.1709)$ & $(0.0435)$ \\
Clear information & $0.9305^{* * *}$ & $0.2258^{* * *}$ \\
& $(1.242)$ & $(0.0612)$ \\
Market/sales & 0.1318 & 0.0319 \\
State policies & $(0.481)$ & $(0.0445)$ \\
Cosservations & $-0.5586^{* *}$ & -0.1355 \\
& $(0.2162)$ & $(0.0561)$ \\
& 0.3967 & \\
\hline
\end{tabular}

Note: $t$ statistics are in parentheses; $* * * p<0.01, * * p<0.05, * p<0.1$

The estimated results from probit model have provided prove about the impact of group factors such as characteristic of household head and household, technical condition, state (state polices, clear information) on the decision of linking GAPs tea production of farmer household in Northern Midland and Mountainous region.

Group factor characteristics of household head and household like education level, the year experiences of household head and the distance from household to the centre of commune 
have negative affection on the decision linking GAPs tea production of household. At significant level 90\%, when the average of education of household head increases one level the probability of selection linkages producing GAPs tea will decrease 19.76\%, same as this characteristic of household head, the year of experience of household raise 1 year, the likelihood of adopt linkages GAPs tea production will sink 1.67\%. These can be explained that the more education level and experience household head have, the higher of independence ability in producing GAPs tea production, the less the probability of linking GAPs tea production. This finding out indicates that when household head have low education level and experience, they want corporate together to reduce the difficult in producing tea in general and particular with GAPs tea which have a lot of tough technical requirement. At significant $95 \%$, the average distance increase $1 \mathrm{~km}$, the probability of linking decrease $1.99 \%$, the farther distance the less linkages by the characteristic of producing tea in Northern midland and mountainous region that tea is usually grown on tea hills, population distribution is often near production. The nearer centre of commune, the more crowded population, the higher probability linkages producing.

Contrary to the negative impact of the above factors, the characteristics of the labor of households, land areas, and household heads who are members of socio-political organizations have a positive influence on the probability of linking GAPs tea production of households. Increasing households labor or tea land area is the driving force for the association decision of household, when the average tea land area increases to 1 ha, the probability of production linkages of households increased by $48.48 \%$ or the number of labor increased by 1 person, the ability to link up by $11.68 \%$. As a member of social organizations, driving the probability of linkage of tea household increase by $17.57 \%$, this may be because when participating in social organizations, the communication network of household heads is expanded. Therefore, the ability to link tea production with other households also increased.

Technical conditions of GAPs tea production is a strict production process with many difficult requirements and regulations that not only affect the decision to produce GAPs tea but also affect the decision to associate GAPs tea production of farmer households. Not all 
farmers in the Northern Midlands and Mountains region can follow GAPs tea production, so with the lower the production conditions, the more likely the households tend to link together, when production conditions are reduced by $1 \%$, the probability of association of households tends to increase by $8.96 \%$ at statistical significant level of $95 \%$.

To encourage farmers to grow GAPs tea, the government often takes support policies. The results show that households receiving material support (fertilizer, pesticide, plant variety ...) positively affect to the linking decision of GAPs tea households $(0.4751 * * *)$. Transparent information about planning, supporting good agricultural practices for tea production is also a driving force for tea production households. The more clear and easily accessible information is, the higher the probability of linkage between tea growing households $(0.2258$ $* * *)$. While the policy of supporting sales and branding seems to be ineffective, this make the higher the linkage between production households $(-0.0896 * *)$.

Interestingly, the GAPs tea consumption factor had no effect on the decision to associate GAPs tea production as a result of this study. While the remaining group factors like the characteristics of household heads and tea producing households, the conditions for producing GAPs tea and the state policies have a statistically significant effect on the decision to link tea production of households. The results of this study have suggested some solutions to promote tea production links of households.

\section{Recommendation}

Tea production GAPs is an indispensable way to enhance the quality of food hygiene and safety and sustainable production in the Northern Midlands and Mountains region, Vietnam. Tea production is still outdated and facing many difficulties, individually producing and the level of association is still loose. Therefore, it is necessary to strengthen the linkage of production among tea households to increase land accumulation, as well as to link production and consumption more effectively, and to help government more easily control instead of the single production form.

Building and developing functional production linkage groups. Linking the groups of households without tea processing machinery or the skills of tea production are not good, or 
difficult to consume... into a group of raw tea producers, only supplying fresh tea to households which have smaller area but have machinery, good skill and have consumption market to ensure output for specialized tea growing group. In order for these two types of functional groups to be interlinked, a clear binding contract, commitment to product quality, commitment to solving arising problems is required.

\section{Reference}

Abdulai, A and Huffman, W (2000), 'Structural Adjustment and Economic Efficiency of Rice Farmers in Northern Ghana', Economic Development and Cultural Change, 48, 503-520

Dao Quyet Thang (2018), Studying the deteminants of the development investment in the agricultural production under GAP-standard at the farmer households: a case study in Ninh Thuan province, Dissertation, National economic university, Ha Noi

Ellis, F., (1993), Peasant Economics: farm households and Agrarian Development, $92^{\text {nd }}$ edition, Cambridge, UK: Cambridge University Press

FAO (1995), 'Integrating wood fuel production into agro forestry extension programs in southeast Asia', Regional wood energy development programs in Asia \& Asia-Pacific agro forestry network, 21

Greene W. H. (2011), Econometric Analysis, Prentice Hall, 7th Edition

General statistic office of Vietnam (2016), statistical yearbook, statistic publisher of Vietnam

Joshep (2013), An analysis of use of Good Agricultural Practices in Rice production: A case study of Bagamoyo and Dakawa Areas Tanzania, A dissertation submitted in partial fulfillment for the degree of Master of science in research methods in Jomo Kenyatta university of Agriculture and technology.

Ngo Huong Giang (2015), Building supply chain for Thai Nguyen tea, Dissertation, Trade Research Institute

Nguyen Thi Phuong Hao (2014), Influence of the change input price on economic efficiency of tea production of farmers in Thai Nguyen province, Doctoral thesis, Thai Nguyen University, Thai Nguyen

Nguyen Bich Hong \& Yabe (2016), "Technical efficiency analysis of Tea production in the northern mountainous region of Vietnam”, Global journal of science frontier research: Agriculture and Veterinary, volume 15

Pongthong P., Yamao, M., Hosono, K. (2014), Factor affecting the implementation of Good Agricultural Practices (GAPs) among coffee farmers in Chumphon province Thailand, American journal of rural development, 2, 34 - 39 
Pham Dinh Hai (2014), Completing the organization and policy to promote good agricultural practices (GAP) in producing fresh tea in Bao Loc city, master's thesis in economics, Forestry University, Lamdong

Sriwichailamphan, T., Sriboonchitta, S., Wiboonpongse, A., and Chaovanapoonphol, Y., (2008), Factors affecting Good Agricultural Practice in Pineapple farming in Thailand, ISHS Acta Horticultural 794: II International symposium on Improving the performance of supply chains in the transitional economies, 794, 325-334,entered on January 02 in 2017, from http://www.actahort.org/books/794/794 40.htm

Ta thi thanh Huyen (2011), Studying the forms of territorial organization of tea production in the Eastern North Region in the direction of sustainable development, Dissertation, National economic university, Hanoi

Tran Quang Huy (2010), Solutions to strengthen cooperation in tea production and consumption in key tea regions of Thai Nguyen province, Dissertation, Hanoi University of Agriculture 